\title{
Research on the Decompression Effects of Shaft Explosion-Proof Door at Different Lifting Heights
}

\author{
Xue-Bo Zhang $\mathbb{D},{ }^{1,2,3,4}$ Shuai-Shuai Shen, ${ }^{1}$ Zhi-Yang Gao $\mathbb{D}^{1},{ }^{1}$ Ming Yang $\mathbb{D},{ }^{1,2,3}$ \\ and Jing-Zhang Ren $\mathbb{1}^{1}$ \\ ${ }^{1}$ College of Safety Science and Engineering, Henan Polytechnic University, Jiaozuo, China \\ ${ }^{2}$ State Key Laboratory Cultivation Base for Gas Geology and Gas Control, Henan Polytechnic University, Jiaozuo, China \\ ${ }^{3}$ State Collaborative Innovation Center of Coal Work Safety and Clean-Efficiency Utilization, \\ College of Safety Science and Engineering, Henan Polytechnic University, Jiaozuo, China \\ ${ }^{4}$ Henan Shenhuo Group Co. Ltd., Yongcheng 476600, China \\ Correspondence should be addressed to Zhi-Yang Gao; gzy@hpu.edu.cn
}

Received 12 May 2021; Revised 25 June 2021; Accepted 19 July 2021; Published 27 September 2021

Academic Editor: Jianwei Cheng

Copyright (c) 2021 Xue-Bo Zhang et al. This is an open access article distributed under the Creative Commons Attribution License, which permits unrestricted use, distribution, and reproduction in any medium, provided the original work is properly cited.

\begin{abstract}
To study the decompression effects of shaft explosion-proof door at different lifting heights, this paper designed the gas explosion testing system. Based on the test results, this paper made a numeric analysis of the change regularities of the shock wave overpressure when the shaft explosion-proof door was lifted at different heights. Finally, this paper determined the proper lifting height of the shaft explosion-proof door and put forward the active decompression concept. The research showed that (1) the shock wave overpressure at the explosion-proof door decreased in a power exponential relationship as the lifting height increased. When the lifting height increased from $0 \mathrm{~cm}$ to $5 \mathrm{~cm}$, the peak overpressure at the explosion-proof door decreased from $36.06 \mathrm{kPa}$ to $22.47 \mathrm{kPa}$, dropping by $37.7 \%$. When it was lifted at a height of $40 \mathrm{~cm}$, the overpressure dropped to $11.20 \mathrm{kPa}$ and the decompression reached $68.9 \%$. (2) The overpressure at the ventilator decreased in a power exponential relationship as the lifting height increased. When the lifting height of the explosion-proof door increased from $0 \mathrm{~cm}$ to $5 \mathrm{~cm}$, the decompression ratio reached the maximum 18.4\%. After that, the decompression effect became worse and worse. (3) The explosion-proof door could depressurize and protect the ventilator at gas explosion but with limited effects. To protect the ventilator and the explosion-proof door to the maximum, it was suggested that the pressure sensor was set up somewhere in the mine where the gas explosion is likely to occur. In this way, the explosion was sensed in time and the explosion-proof door could be actively lifted for decompression. This paper was of great guiding significance in optimizing the design of the explosion-proof door equipment, reducing the loss of gas explosion accidents as well as carrying out the emergency rescue.
\end{abstract}

\section{Introduction}

The gas explosion of the underground coal mine is one of the major disasters in coal mines, which poses a great threat to the life safety of underground workers. The prevention and suppression of explosion are a major research topic in the field of underground coal mining [1-3]. Explosion-proof door is an important part of the coal mine ventilation system. In the case of underground gas explosion, the explosion-proof door can be lifted quickly to release pressure and reduce the damage to the ventilator. Also, the door can be closed quickly after the shock wave to create conditions for postdisaster rescue [4]. Therefore, it is very important to ensure the stable operation of the ventilation system and remove the harmful and poisonous gas after the explosion accident.

At present, the cover-type explosion-proof door is still mainly used in the return air shaft of the coal mine. Gas explosions have happened in mines with different gas grades, and they have caused damage to the cover-type shaft explosion-proof doors [5]. For example, at Xinhua No. 4 mine (low gas level) in Pingdingshan City, the explosion-proof door was lifted and dislocated after falling. At Taiyuan Tunlan coal mine (high gas level), the 
explosion-proof door was driven hundreds of meters away, and the deviation was over 20 meters. Explosions continuously occurred at Chenjiashan coal mine (outburst mine) in Tongchuan City, Shanxi Province. In the explosions, the explosion door was driven hundreds of meters away and the ventilator got damaged. Therefore, it is of great practical significance for the explosion-proof door to timely release pressure and reset after explosion accidents because it not only reduces the casualties and losses of the accidents but also facilitates the emergency rescue.

Many scholars have carried out considerable detailed studies on the law of underground shock wave motion. According to the experiment, Savinko put forward the attenuation formula of shock motion intensity in straight roadways and pointed out that the speed of shock wave pressure attenuation mainly depended on the size, structure, and support pattern of the fractured surface [6]. Baiquan et al. systematically studied the effects of different roadway conditions on gas explosion through experimental methods. Their research showed that obstacles could aggravate the turbulence effect in the flame transmission process, thus causing the positive feedback mechanism in the explosion process [7-10]. Bin et al. studied the influence of $\mathrm{C}_{2} \mathrm{H}_{4}$ and $\mathrm{H}_{2}$ on premixed gas explosion through experiments, and the research results play a guiding role in chemical industry explosion prevention [11-13]. In the design of a gate-type explosion-proof door, Hu determined its counterweight through force analysis and sealed it with plate-type rubber strips [14]. Xuebo et al. designed a shaft explosion-proof door of return air with buffering and resetting functions. Through hydraulic devices, the device could effectively reduce the damage of the shock wave to the ventilation door and increase its reliability [15]. Qiusheng et al. established an overturning model of the explosion-proof door body by analyzing the stress relationship of the door body in the mine [16]. Through numerical simulation, Jiajia et al. proposed that a linear relationship existed between the gas accumulation amount and the peak overpressure at the fan and the explosionproof door and that the peak overpressure would increase along with the increase of the gas accumulation amount [17]. Tian et al. first established the MFBL explosion-proof door model, and then they simulated and analyzed the relationship between the lifting height of the explosionproof door and the explosion equivalent through the Fluent software [18].

Scholars have carried out a lot of studies on the law of the shock motion in the gas explosion, and some scholars have studied the new explosion-proof doors. At present, the widely used cover-type shaft explosion-proof doors are overall relatively low in the protection efficiency. However, few scholars have carried out research on how the explosion-proof door is actively lifted to release pressure. This paper analyzed the decompression effects of the explosion-proof door at the door itself and the ventilators at its different lifting heights and put forward the concept about the active opening of the explosion-proof door. The research results provided theoretical support for improving the decompression effects of the explosionproof door and optimizing the design of the explosionproof door equipment.

\section{Gas Explosion Experiment System Design and Experiment Result Analysis}

The team independently developed the gas explosion experiment system, which is composed of return air roadway, return air shaft, ventilator, explosion-proof door, ignition device, high-frequency dynamic pressure transmitter, high-speed camera, etc., as shown in Figure 1. The return air shaft and air drift are round pipes with a diameter of $40 \mathrm{~cm}$, and the return air roadway is semicircular pipes with a radius of $20 \mathrm{~cm}$.

Experimental procedures: (1) a methane-air mixture with a certain concentration was prepared by using the flow meter and the pressure gauge. The gas mixture was filled in the first section of the pipeline with preinstalled film through exhausting air, length $1 \mathrm{~m}$ (as shown in Figure 1). The methane concentration of mixed gas was 9.5\% filled with the exhaust air method. Also, the aeration time was $4.46 \mathrm{~min}$. (2) The power of the ignition device is switched on, and the spark ignition device was controlled with computers. The high-frequency dynamic pressure transmitter on the pipe wall started to collect data. The ignition point time was recorded as 0 s. In the coordinate system shown in Figure 1, the coordinates of each monitoring point are $P 1(70,20), P 2$ $(0,110), S Z(310,20)$, and BZ $(460,15)$. In order to protect the experimental equipment, the opening height of the explosion-proof door is $100 \mathrm{~cm}$. (3) Data collected by using the high-frequency dynamic pressure transmitter were extracted and summarized for analysis.

In the experimental process, the flame transmission of the shock wave in the gas explosion is shown in Figure 2, and the shock wave overpressure changes in the blast zone (BZ) and the spread zone (SZ) are shown in Figure 1.

As can be seen from Figure 2, the flame plane first expanded in a spherical shape after the premixed gas was ignited. Limited by the pipeline, the flame plane would then transform into a rugby shape and propagate forward. It can be seen from Figure 2 that the shock wave had the obvious reflection effect when it transmitted to the return air roadway and the turning point of the return air shaft. This indicated that part of the shock wave energy was transferred to the return air shaft and some energy was reflected to the return air shaft in the form of reflection, and the remaining energy was transmitted to the air in the form of sound wave, thermal radiation, and heat transfer.

As shown in Figure 3, (1) after the gas explosion, the overpressure reached the peak value at an approximate time in the explosion zone and the transmission zone. This was the interaction result of a small experimental model and high transmission speed of shock wave. (2) It can be seen from the development of the shock wave that the shock wave overpressure in the explosion transmission zone was greater than that in the explosion area. This was because the shock wave in the blast zone had not yet developed to the maximum. When the reaction of all the 


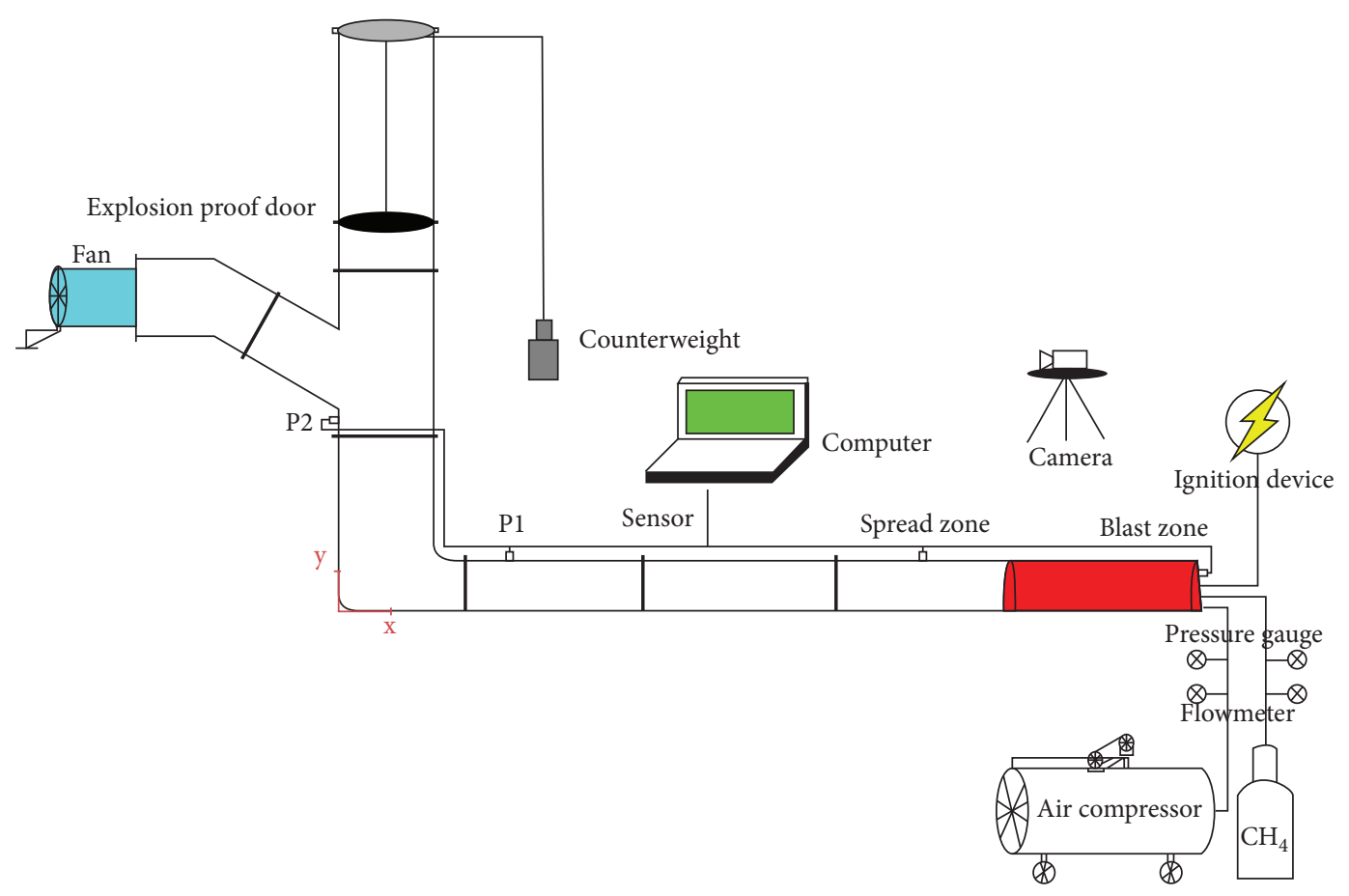

FigURE 1: Gas explosion experiment system.

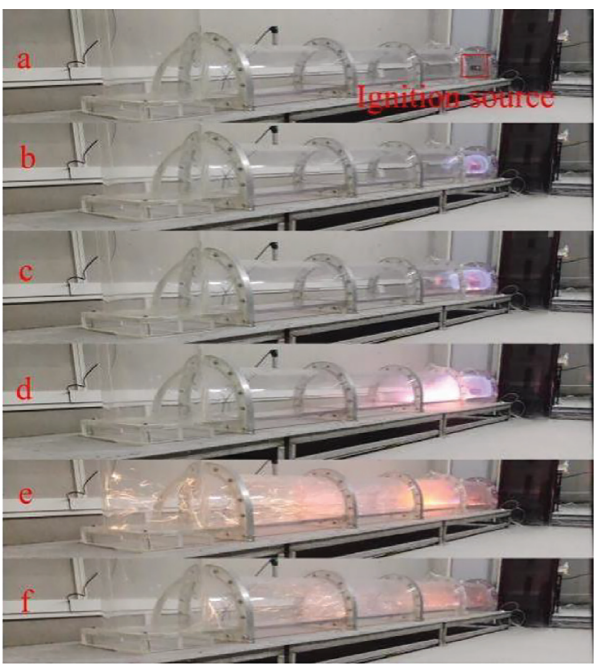

FIgURE 2: The flame transmission of the shock wave.

accumulative gas finished, the shock wave overpressure reached the peak value, so the peak value in the transmission area was relatively great. Because of the shock motion, the overpressure became negative in the blast zone and the transmission zone, and the maximum negative pressure in the transmission zone was smaller than that in the blast zone. This was because it took some time for the shock wave to transmit from the blast zone to the transmission zone. As can be seen from Figure 3, the rising speed curve of the overpressure in the blast zone rose became negative, which was slightly before the curve in the transmission area. (3) The rising speed of the overpressure in both zones fluctuated at $100 \mathrm{~ms}$ because the size of the gas explosion experiment system was small. The

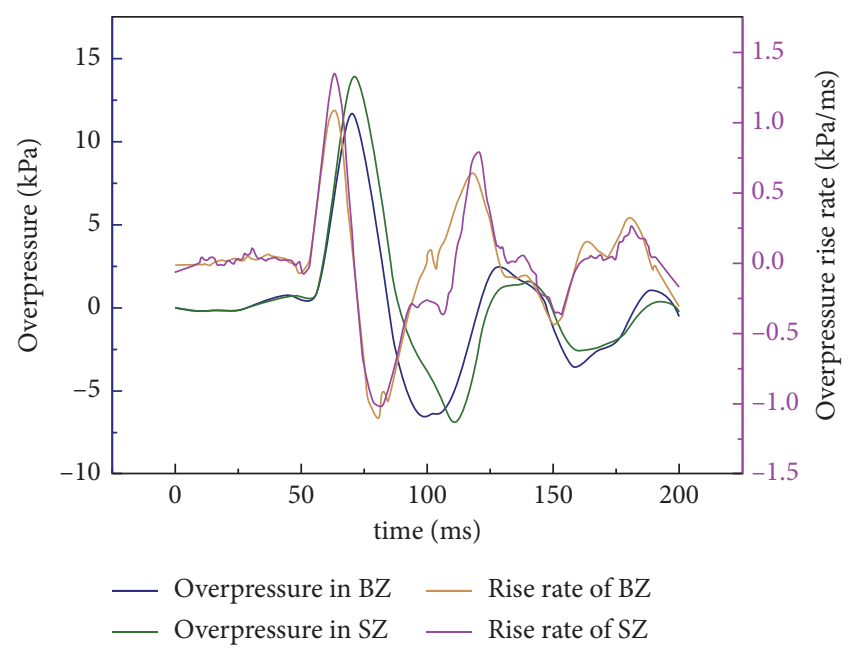

Figure 3: Overpressure change diagram in the experimental process.

monitoring points of both zones were within the coverage of the shock wave reflection, and the distance between the transmission zone and the corners was shorter, so the fluctuation got more obvious.

\section{Decompression Effect Analysis of Explosion- Proof Door at Different Lifting Heights}

\subsection{Mathematical Model Building and Verification}

3.1.1. Mathematical Model Building. Gas explosion can be assumed to be an ideal gas heated accelerated expansion process, which can be described by a mathematical model composed of kinetic process control equation (mass 
conservation equation, momentum conservation equation, energy conservation equation, and component balance equation), turbulence model, and gas chemical reaction model (combustion model and turbulence flame velocity model).

The turbulence model includes $k-\varepsilon$ model, LES model, and DES model. Gas chemical reaction models include laminar flow finite rate model, eddy-dissipation model, laminar flow finite rate/eddy-dissipation model, and EDC model. The laminar finite rate model uses the Arrhenius formula to calculate the chemical source terms but ignores the influence of turbulence fluctuation, so it is suitable for simulating laminar flame propagation. The eddy-dissipation model (EDM) can simulate the rapid combustion of most fuels, and the overall reaction rate is controlled by turbulent mixing. When the LES turbulence model is used (LES + eddydissipation model), turbulent mixing rate is replaced by subgrid-scale mixing rate, which can better simulate the propagation process of gas explosion shock wave. The eddydissipation concept (EDC) model is an extension of eddydissipation model, which can simulate the turbulent reaction flows with chemical reaction mechanisms. However, typical mechanisms have different rigidity, their numerical integration calculation is very expensive, and the model can only be used when the fast chemical reaction is assumed to be invalid. Therefore, the LES turbulence model and eddy-dissipation model (EDM) are finally adopted to simulate the propagation law of gas explosion shock wave.

Combustion model and turbulent flame velocity model:

$$
\begin{aligned}
R_{\mathrm{fu}} & =-\min \left(|R|,\left|R_{j, \mathrm{fu}}\right|\right), \\
R_{i, \mathrm{fu}} & =v_{i, \mathrm{fu}}^{\prime} M_{\omega, i} A \rho \tau^{-1} \operatorname{sgs} \min \left(\frac{Y_{i, \mathrm{fu}}}{v_{i, \mathrm{fu}} M_{\omega, \mathrm{fu}}}\right), \\
R_{j, \mathrm{fu}} & =v_{j, \mathrm{fu}}^{\prime} M_{\omega, j} A B \rho \tau^{-1} \operatorname{sgs} \frac{\sum_{j} Y_{j, \mathrm{fu}}}{\sum_{j}^{N} v_{j, \mathrm{fu}}^{\prime \prime} M_{\omega, j}}, \\
\tau^{-1} \mathrm{sgs} & =\sqrt{2 S_{i j} S_{i j}},
\end{aligned}
$$

where $Y_{i, f u}$ is the mass fraction of any production species, $Y_{j, \text { fu }}$ is the mass fraction of a particular reactant, $A$ and $B$ are empirical constants equal to 4.0 and 0.5 , respectively, $\tau^{-1} \mathrm{sgs}$ is the subgrid-scale mixing rate, and $S_{i j}$ is the strain rate tensor.

The gas explosion is an unsteady process, and there was no slip on the model wall. A simple algorithm was adopted for iterative solution, and the iteration step size was $0.0005 \mathrm{~s}$.

3.1.2. Physical Model. According to the gas explosion experiment system, a geometric model with a size of $1: 1$ was established, as shown in Figure 4. Different lifting heights of explosion-proof doors were selected based on the diameters of the roadways. The experiment established the geometric models of explosion-proof doors at lifting heights of $0 \mathrm{~cm}$ (nonlifting), $5 \mathrm{~cm}, 10 \mathrm{~cm}, 20 \mathrm{~cm}, 30 \mathrm{~cm}, 40 \mathrm{~cm}$, and $\infty \mathrm{cm}$ (no explosion-proof door).

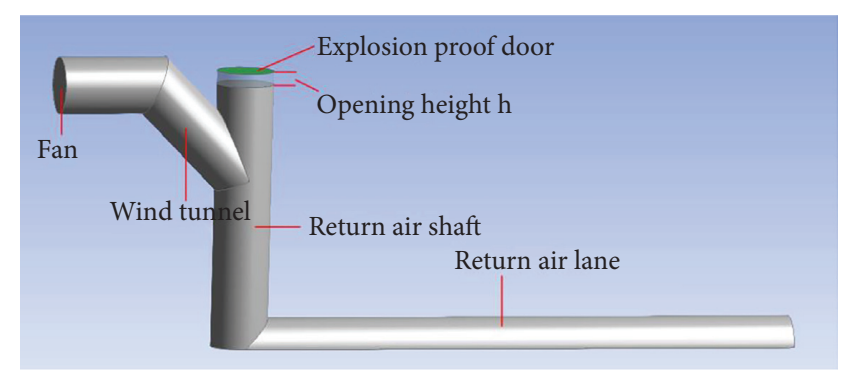

FIgUre 4: Physical model diagram.

The initial conditions are as follows:

(1) The initial pressure of the whole region is $0 \mathrm{~Pa}$ relative to the atmospheric pressure

(2) The initial temperature is $300 \mathrm{~K}$

(3) The initial velocity of the whole area is $0 \mathrm{~m} / \mathrm{s}$

(4) The whole area is full of air

The boundary conditions are as follows:

(1) The outlet of the fan is set as pressure outlet, and the outlet pressure is $0 \mathrm{~Pa}$ relative to atmospheric pressure

(2) The standard wall function is adopted for the near wall surface, and the explosion-proof door is set to be nonsliding wall surface

The gas explosion processes of these seven geometric models were simulated, respectively, and the influence of explosion-proof doors' lifting heights on the decompression effect of shock waves was analyzed.

3.1.3. Mathematical Model Verification. In Section 2, the propagation characteristics of shock wave in the blast zone and spread zone are revealed. In order to verify the applicability of the mathematical model, numerical simulation was carried out based on the experiment. The experimental results at $P 1$ and $P 2$ in Figure 1 are compared with the simulation results to verify the correctness of the established model. The experimental results and the numerical simulation results are compared as shown in Figure 5.

In Figure 5, the position of $P 1$ and $P 2$ is shown in Figure 1; it could be known from the numerical simulation results and the experimental results that the shock wave attenuation laws were basically identical, but the peak value of the overpressure was relatively greater in the numerical simulation. This was mainly because the walls of the roadways were set up as no slipping and no heat transfer. However, the energy produced from the gas explosion was transmitted to the environment through heat transfer or vibration in the experiment. Therefore, the simulated result was relatively greater. This proved the reliability of the established mathematical model for gas explosion.

3.2. Research on the Decompression Effects of the ExplosionProof Door at Different Lifting Heights. At different lifting heights, the cloud chart about the overpressure in the 


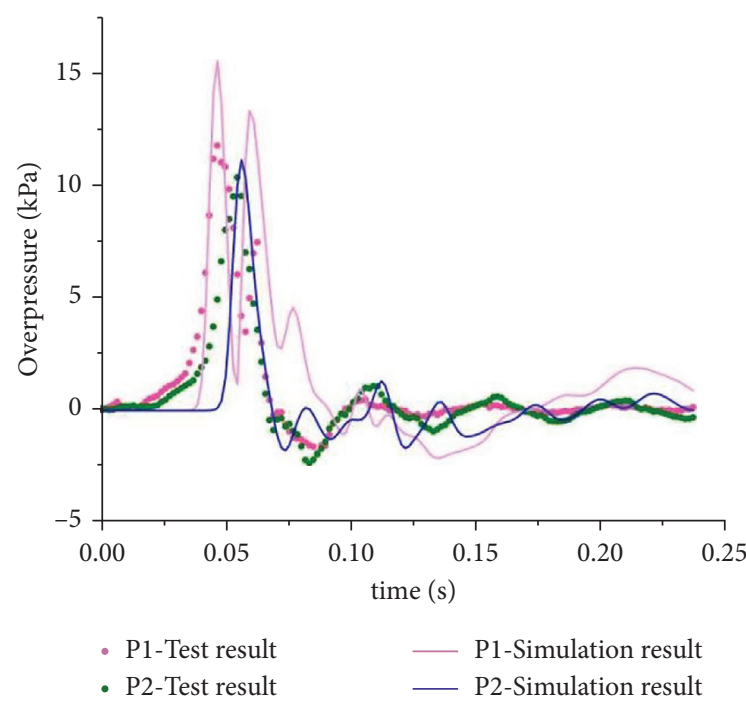

Figure 5: Comparison diagram of experimental results and simulation results.

cross section of the roller and the overpressure changes at the monitoring points are shown in Figures 6 and 7 when the overpressure reached the maximum at the explosionproof door.

It can be seen from Figures 6 and 7 that (1) as the lifting height of the explosion-proof door increased, the area where the overpressure reached the maximum at the explosion-proof door became smaller and smaller, namely, the decompression area got larger near the explosion-proof door. (2) As the lifting height of the explosion-proof door increased, the peak value of the overpressure near the explosion-proof door decreased gradually at an increasingly low speed; when the lifting height of the explosion-proof door increased from $0 \mathrm{~cm}$ to $5 \mathrm{~cm}$, the peak value of the explosion-proof door decreased from $36.06 \mathrm{kPa}$ to $22.47 \mathrm{kPa}$, and the overpressure peak value decreased by $38 \%$. When the lifting height of the explosion-proof door increased from $30 \mathrm{~cm}$ to $40 \mathrm{~cm}$, the overpressure decreased from $12.64 \mathrm{kPa}$ to $11.20 \mathrm{kPa}$, and the overpressure decreased by $11.4 \%$. A power exponential relationship existed between the peak overpressure at the explosion-proof door and the lifting height, and the equation was $y=37.69 \times x^{-0.032}$. (3) As the lifting height of the explosion-proof door increased, the second peak of the overpressure change curve would also decrease, and the decline rate decreased with the increase of the lifting height. It showed that as the lifting height of the explosion-proof door increased, the reflection peak value between the explosion-proof door and the shock wave gradually weakened. A power exponential relationship existed between the reflection overpressure peak value and the lifting height, and the equation was $y=14.14 \times(x+2.25)^{-0.55}$. In conclusion, with the increase of the opening height of the explosion-proof door, the decompression effect near the explosion-proof door is more obvious. Also, the pressure relief efficiency decreases with the increase of opening height and approaches to 0.
3.3. Analysis on the Decompression Effects of the Ventilator at Different Lifting Heights. At different lifting heights, the cloud chart of the overpressure and the overpressure changes at the monitoring points are shown in Figures 8 and 9 when the overpressure reached the maximum at the ventilator.

By comparing the changes of the explosion-proof door at different lifting heights, it can be seen from Figures 8 and 9 that (1) as the lifting height of the explosion-proof door increased, the area that reached the maximum overpressure near the ventilator decreased slightly. The peak overpressure was $11.17 \mathrm{kPa}$ at the ventilator when the explosion-proof door was not opened, but it was $8.60 \mathrm{kPa}$ at the ventilator without the explosion-proof door. This indicated that the opening height of the explosion-proof door had little effect on the overpressure distribution near the ventilator. (2) The peak overpressure decreased at low speed along with the increase of the lifting heights. When the lifting height increased from $0 \mathrm{~cm}$ to $5 \mathrm{~cm}$, the overpressure distribution diagram showed the most obvious changes near the ventilator, and the overpressure decreases most at the ventilator. The peak overpressure decreased from $11.17 \mathrm{kPa}$ to $9.11 \mathrm{kPa}$ at the ventilator, which decreased by $18.4 \%$. The subsequent increase in the lifting height of the explosion-proof door had little influence on the overpressure at the ventilator. When the lifting height increased from $30 \mathrm{~cm}$ to $40 \mathrm{~cm}$, the peak overpressure decreased from $8.70 \mathrm{kPa}$ to $8.60 \mathrm{kPa}$ at the ventilator, dropping by $1 \%$. A power exponential relationship existed between the peak overpressure at the ventilator and the lifting height, and the fitting equation was $y=9.48 \times(x+0.002)^{-0.03}$. (3) In Figure 9(b), $y^{\prime}$ is the derivative of the overpressure fitted curve at the ventilator. It can be seen from the curve that the peak overpressure satisfied the following condition: $y^{\prime}<0 .\left|y^{\prime}\right|$ is the absolute value of $y^{\prime} .\left|y^{\prime}\right|$ was relatively great in value when the lifting height of the explosion-proof door was relatively small in value. Along with the increase of the lifting height, the overpressure rapidly reduced and was approximated to 0 . As a result, the overpressure reduction rate at the ventilator gradually decreased and was approximated to 0 .

\section{Proposal of the Active Opening Concept of the Explosion-Proof Door}

4.1. The Reasonable Lifting Height Computation of the Explosion-Proof Door. The reasonable lifting height of the explosion-proof door is mainly determined by the maximum overpressure borne by the explosion-proof door and the ventilator. Suppose that the return air shaft is a circular shaft with the diameter of $2 R$ and the shorn cross-sectional area of the joint part is $A$, then the explosion-proof door bears local resisting shear stress [19]:

$$
\Delta P_{r} \leq \frac{A \tau_{s}}{\left(\pi R^{2}\right)} .
$$

In the equation, $\tau_{s}$ is the shear strength of the explosionproof door, $\tau_{s} \approx \sigma_{s} / \sqrt{3}$, and $\sigma_{s}$ is the yield limit of the explosion-proof door. 

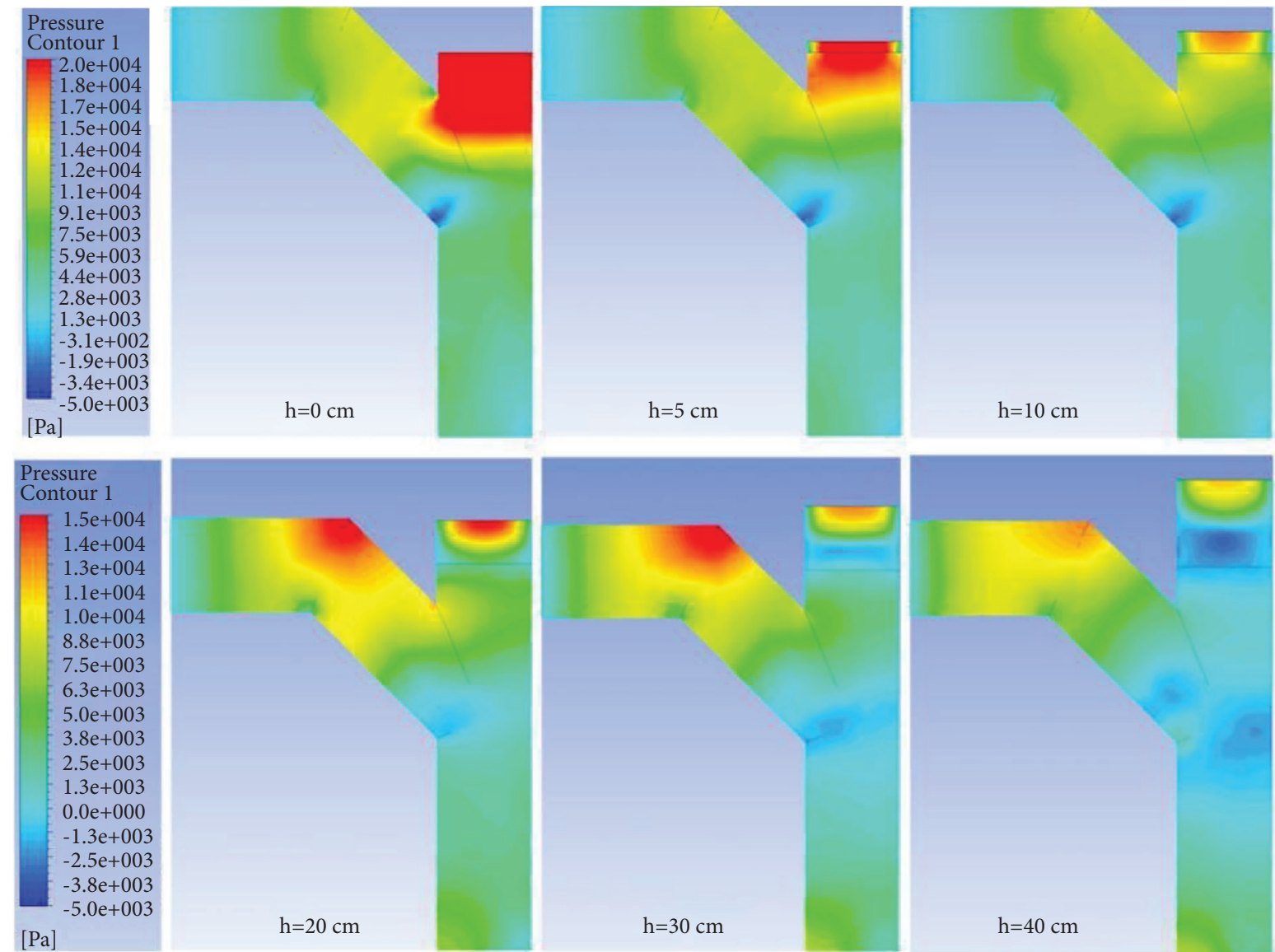

Figure 6: Cloud chart about the overpressure distribution of the explosion-proof door at different lifting heights.

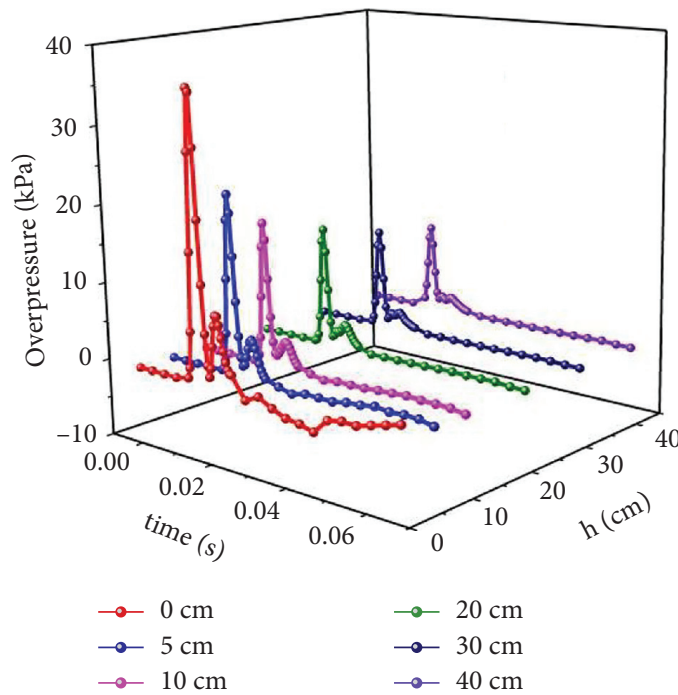

(a)

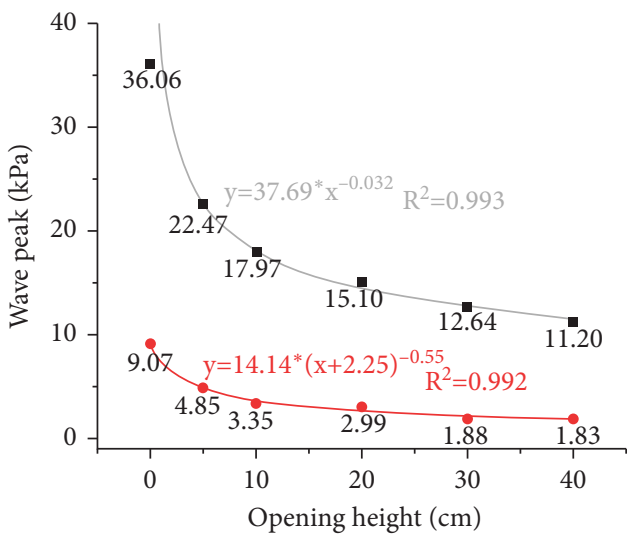

- First wave peak

- Second wave peak

- First wave peak fitting

_ Second wave peak fitting

(b)

Figure 7: (a) Overpressure change curve and (b) peak value fitting diagram.

When the shock wave reached the lower side of the explosion-proof door, the stress borne by the door body included the upward impact force produced by the overpressure and the downward gravity produced by the weight of the door itself. To simplify the computation, the model was simplified as a circular plate with a radius of $R$ and simple support around it. The following can be obtained according to the force balance: 

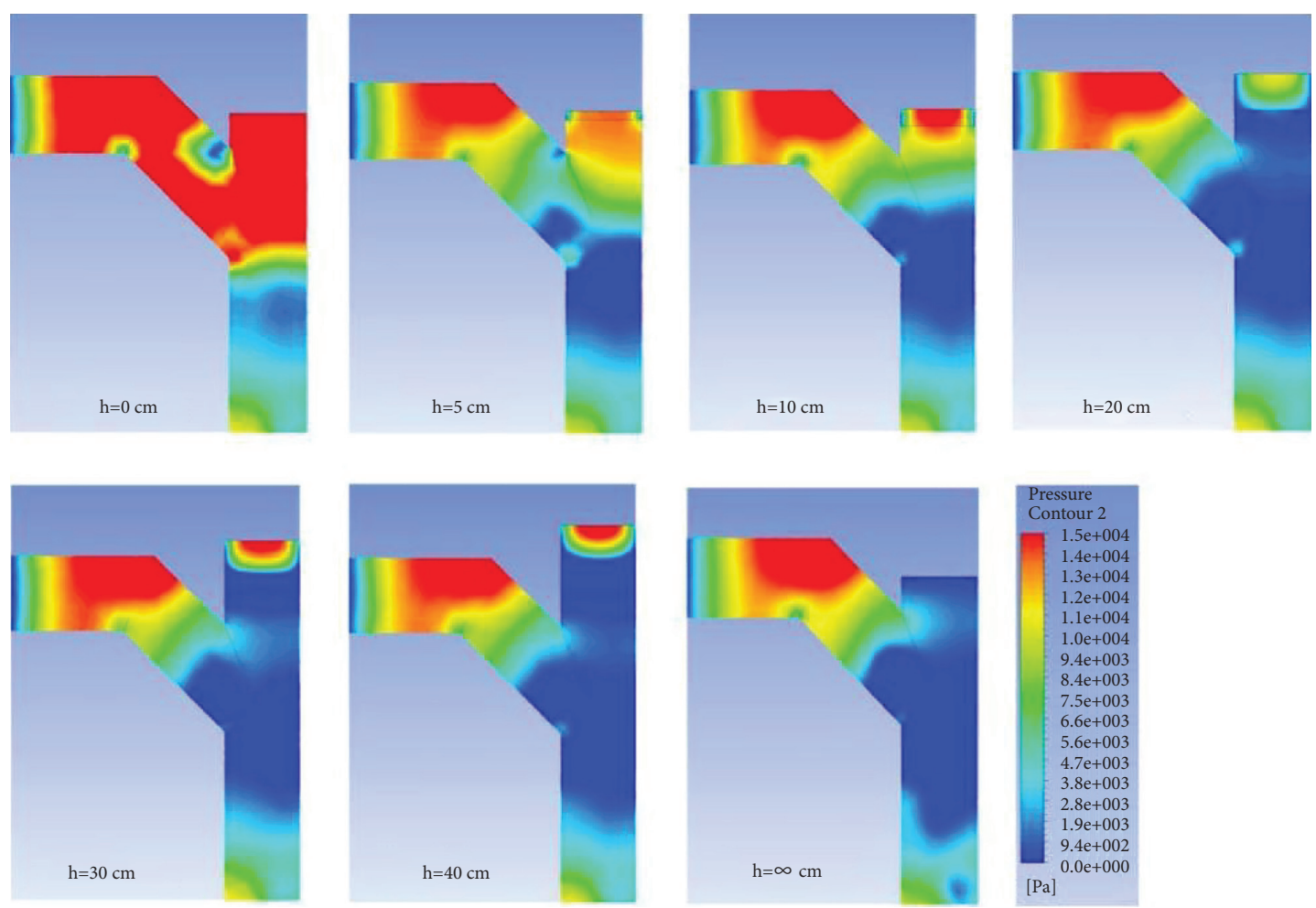

Figure 8: Cloud chart about the overpressure distribution of the ventilator at different lifting heights.

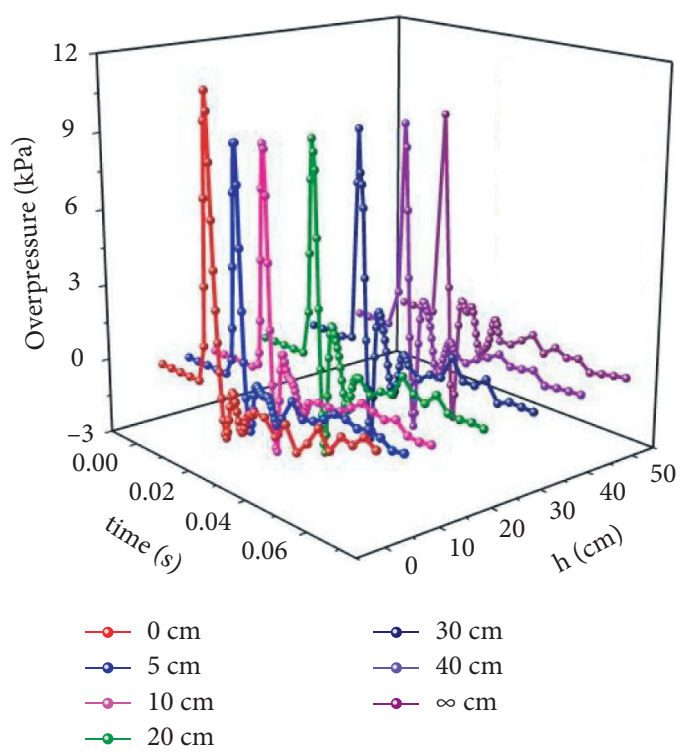

(a)

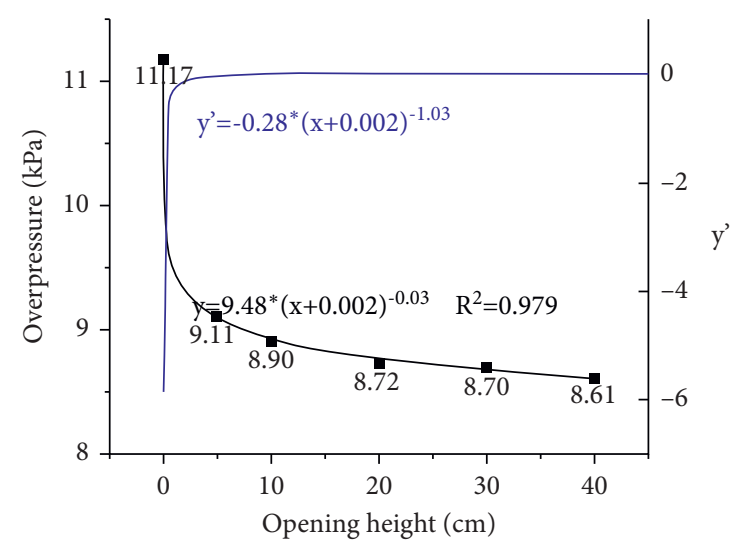

- Overpressure

- Overpressure fitting

$-y^{\prime}$

Figure 9: (a) Overpressure change curve and (b) peak value fitting diagram.

$$
p-\delta \rho_{x} g=\Delta P_{x}
$$

In the equation, $\delta$ is the thickness of the door plate, $\rho_{x}$ is the steel plate density of the explosion-proof door, and $g$ is the acceleration of gravity. Thus, the maximum overpressure borne by the door plate was as follows:

$$
p \leq \frac{\delta \rho_{x} g+A \sigma_{s}}{\left(\sqrt{3} \pi R^{2}\right)}
$$

The explosion-proof doors are mainly made of low carbon steel, with $\sigma_{s}=225 \mathrm{MPa}$, density $\rho_{x}=7800 \mathrm{~kg} / \mathrm{m}^{3}$, and $g=9.8 \mathrm{~m} / \mathrm{s}^{2}$. The radius of the return air shaft $R$ is $0.2 \mathrm{~m}$, 
TABLE 1: $\left|y^{\prime}\right|$ values of different opening heights.

\begin{tabular}{lc}
\hline Opening heights $(\mathrm{cm})$ & $\left|y^{\prime}\right|(\%)$ \\
\hline 1.01 & 27.7 \\
5 & 5.3 \\
10 & 2.6 \\
20 & 1.3 \\
\hline
\end{tabular}

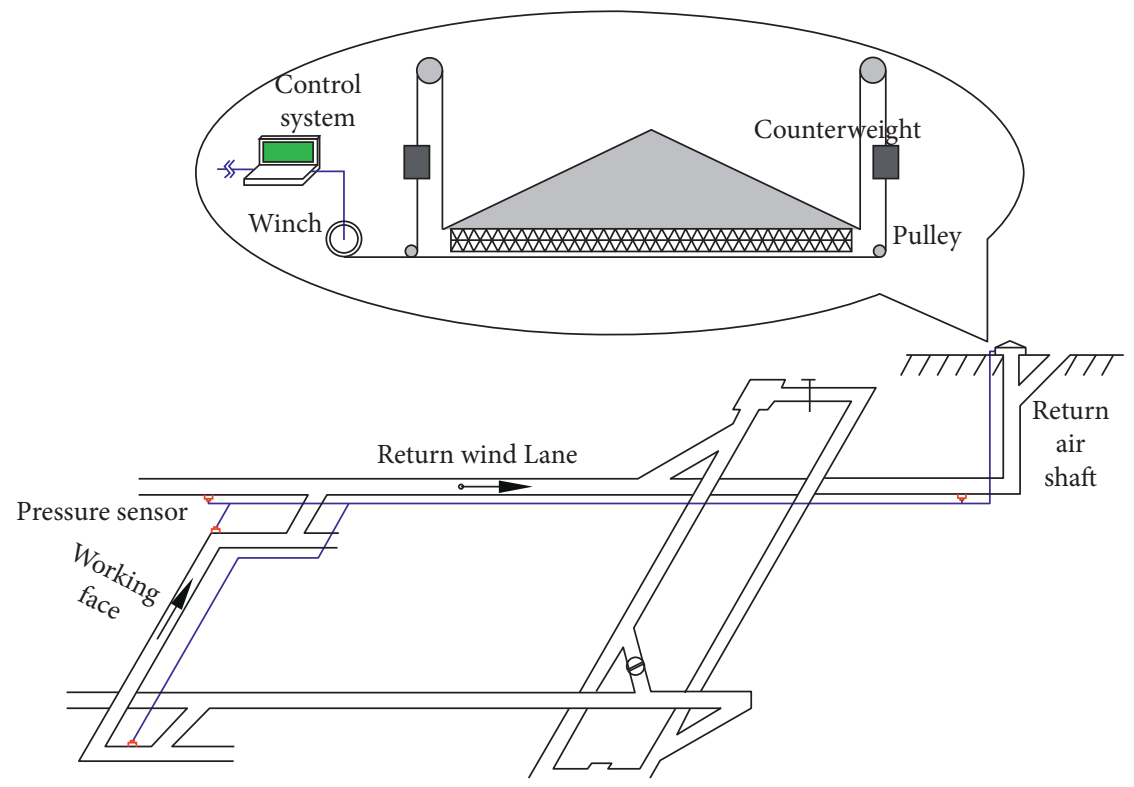

Figure 10: Active opening schematic diagram of the explosion door.

the thickness of the explosion-proof door is $0.15 \mathrm{~cm}$, and the shorn part is basically a rectangle with a dimension of $0.15 \mathrm{~cm} \times 1.5 \mathrm{~cm}$, so we can calculate that the overpressure by the door plate was $23.37 \mathrm{kPa}$.

When the overpressure $23.37 \mathrm{kPa}$ was substituted into the fitted equation $y=37.69 \times x^{-0.032}$ of the maximum overpressure borne by the explosion-proof door and the lifting height, $h \geq 1.01 \mathrm{~cm}$ was obtained. Namely, when the lifting height of the explosion-proof door exceeded $1.01 \mathrm{~cm}$, it could effectively prevent the damage caused by the shock wave to the explosion-proof door. When the lifting height of the explosion-proof door $(1.01 \mathrm{~cm})$ was substituted into the fitted equation $y=9.48 \times(x+0.002)^{-0.03}$ of the overpressure value at the ventilator and the lifting height changes of the explosion-proof door, the overpressure at the ventilator $(9.47 \mathrm{kPa})$ was obtained. The image of $y^{\prime}$ is shown in Figure 9(b). The values of $\left|y^{\prime}\right|$ in different opening heights are shown in Table 1.

From Table 1, we can know that when the opening height is greater than $5 \mathrm{~cm}$, the $\left|y^{\prime}\right|$ value is less than $5 \%$, namely, the increase of subsequent open height on the fan pressure effect is not obvious. In order to protect the fan and the explosion-proof door at the same time, the opening height of the explosion-proof door should not be less than $5 \mathrm{~cm}$.

4.2. The Active Opening Concept of the Explosion-Proof Door. Based on the research results, the opening of the explosionproof door could better relieve the pressure in the area near the explosion-proof door, but the decompression effect at the main ventilator is poor. When the lifting height of the explosion-proof door increased from $0 \mathrm{~m}$ to $40 \mathrm{~cm}$, the overpressure at the explosion-proof door decreased by $68.9 \%$, but the overpressure at the ventilator only dropped by 22.9\%. The cover-type shaft explosion-proof door cannot effectively protect the ventilator. However, the cover-type shaft explosion-proof doors are still widely used in China. To maximize the decompression effect and protect the ventilator to the maximum, it is suggested that the pressure sensors are installed in places (stope face, coal face, etc.) where gas explosions easily happen underground, and they are connected with the mine monitoring system. Meanwhile, the explosion-proof door should also have the automatic quick-opening function. The automatic opening of the explosion-proof door and the monitoring data of the sensor are coordinately controlled. Once the monitoring system senses the gas explosion and the explosion strength reaches a certain value, the explosion-proof door could open actively and rapidly to release the pressure before the shock wave arrives. Moreover, the explosion-proof door is lifted to a reasonable height to achieve the best decompression effect so that the main ventilator and the explosion-proof door are well protected, reducing the losses caused by explosion accidents. The implementation method is shown in Figure 10.

As shown in Figure 10, the pressure sensor is installed at the position where gas accumulation is easy to occur, and the winch and pulley block are installed at the wellhead. When 
the gas explosion occurs, the pressure sensor detects the sudden change of pressure and transmits it to the ground control system through the optical fiber signal cable. The control system converts the photoelectric signal into power through the winch. The winch realizes the horizontal lifting of the explosion-proof door through the cable and pulley block connected under the counterweight of the explosionproof door, so as to achieve the purpose of protecting the explosion-proof door.

\section{Conclusions}

(1) The gas explosion experiment system was independently developed to study the law of shock wave overpressure changes in the blast zone and transmission zone during the gas explosion. By comparing the experimental results with the simulation results, this experiment also verified the applicability of establishing the mathematical model for gas explosion.

(2) This paper also analyzed the decompression effects of both the explosion-proof door and the ventilator at different lifting heights. The opening of the explosion-proof door could better release the pressure borne by the door, but the decompression effect at the main ventilator was poor. When the lifting height of the explosion-proof door increased from $0 \mathrm{~m}$ to $40 \mathrm{~cm}$, the overpressure at the explosion-proof door decreased by $68.9 \%$, but the overpressure at the ventilator only decreased by $22.9 \%$. The shock wave overpressure at the explosion-proof door and the ventilator decreased in a power exponential relationship as the lifting height of the explosion-proof door increased. With the increase of the lifting height, the overpressure decrease rate gradually became smaller.

(3) This paper put forward the active opening concept of the explosion-proof door and calculated its reasonable lifting height. To maximize the decompression effect of the explosion-proof door and protect the ventilator to the maximum, it is suggested that the pressure sensors are installed in places (stope face, coal face, etc.) where gas explosions easily happen underground. Meanwhile, the explosionproof door automatically and quickly opens and achieves the coordinated control together with the sensor data. The explosion-proof door could open actively and rapidly at the reasonable lifting heights to release the pressure before the shock wave arrives, reducing the losses caused by explosion accidents. The research results can provide theoretical support for improving the decompression effect of explosionproof doors and optimizing the design of explosionproof door equipment.

\section{Data Availability}

All the data used to support the findings of this study are available from the corresponding author upon request.

\section{Conflicts of Interest}

The authors declare that there are no conflicts of interest regarding the publication of this paper.

\section{Acknowledgments}

This study was supported by the National Key Research and Development Program of China (grant no. 2018YFC0808103), the National Natural Science Foundation of China (grant nos. 51734007, 51704099, and 52074106), the Program for Innovative Research Team in University of Ministry of Education of China (grant no. IRT_16R22), the Key R\&D and Promotion Projects in Henan Province (grant no. 212102310105), and the Doctoral Fund of Henan Polytechnic University (grant no. B2019-56).

\section{References}

[1] X. Jingde, Study on Propagation Law and Influencing Factors of Shock Wave of Mine Gas Explosion, China University of mining and Technology, Beijing, China, 2003.

[2] H. Tiezhu, Numerical Simulation of Gas Explosion Propagation Law, China University of mining and Technology, Beijing, China, 2008.

[3] L. Weixin, L. Bao, and W. Lei, "Study on overpressure and temperature distribution in Roadway after gas explosion in coal mine," Coal Science and Technology, vol. 40, no. 452, pp. 41-43, 2012.

[4] S. Weibin and S. Yuning, "Analysis on development status of explosion-proof door in vertical air shaft of coal mine," China Science and technology of work safety, vol. 11, no. 6, pp. 108-114, 2015.

[5] S. Weibin, Research on Safety protection Theory and Technology of Mine Shaft Explosion Proofdoor, Henan University of technology, Zhengzhou, China, 2018.

[6] C. Savinko, Underground Air Shock Wave, Metallurgical Industry Press, Beijing, China, 1979.

[7] L. Baiquan, Z. shining, and Z. Rengui, "The fluence of barriers on flame and explosion wave ingas explosion," Journal of Coal Science and Engineering, vol. 2, pp. 53-57, 1998.

[8] L. Baiquan, "Determination and analysis of dynamic characteristic parameters of gas explosion," Journal of coal industry, vol. 2, pp. 164-167, 2002.

[9] L. Baiquan, Z. shining, and Z. Rengui, "Induction condition and analysis of shock wave during gas explosion," Experimental Mechanics, vol. 24, pp. 36-41, 1998.

[10] L. Baiquan, Z. Shining, and Z. Rengui, "Influence of obstacles on flame and explosion wave during gas explosion," Journal of China University of mining and technology, vol. 2, pp. 3-5, 1999.

[11] S. Bin, L. Zhenmin, W. Tao, C. Xie, and F. Cheng, "Chemical kinetic behaviors at the chain initiation stage of Ch4/h2/air mixture," Journal of Hazardous Materials, vol. 403, 2021.

[12] W. Tao, L. Zhenmin, W. Hu et al., "The explosion enhancement of methane-air mixtures by ethylene in a confined chamber," Energy, vol. 214, 2021.

[13] W. Tao, Z. You, L. Zhenmin et al., "Flammability limit behavior of methane with the addition of gaseous fuel at various relative humidities," Process Safety and Environmental Protection, vol. 140, 2020. 
[14] H. Hao, W. Kezhi, and B. Hongfeng, "Design of new explosion proof door for return air shaft in coal mine," Coal, vol. 23, no. 11, pp. 43-44, 2014.

[15] Z. Xuebo, S. Shuaishuai, and Y. Ming, "Return air shaft explosion-proof door with buffer and reset function," 2020.

[16] L. Qiusheng, L. Kai, and Y. Guiying, "Analysis of explosion impact force on explosion proof cover," Coal mine safety, vol. 46, no. 4, pp. 213-214, 2015.

[17] L. Jiajia, C. Shouqi, and R. Jingzhang, "Study on the influence of gas accumulation and explosion distance on fan and explosion door," China Science and technology of work safety, vol. 16, no. 9, pp. 57-63, 2020.

[18] Q. Tian, P. Rongkun, and G. Qiuyue, "Simulation study on pressure relief of MFBL explosion door under different explosion conditions," Journal of Nanjing University of Technology (Natural Science Edition), vol. 43, no. 2, pp. 177-183, 2021.

[19] F. Xisheng, "Research on mine automatic reset air shaft explosion proof door," Coal Science and Technology, vol. 40, no. 6, pp. 58-61, 2012. 